Article

\title{
In Vitro Testing of Scaffolds for Mesenchymal Stem Cell-Based Meniscus Tissue Engineering-Introducing a New Biocompatibility Scoring System
}

\author{
Felix P. Achatz ${ }^{1}$, Richard Kujat ${ }^{1}$, Christian G. Pfeifer ${ }^{1}$, Matthias Koch ${ }^{1}$, Michael Nerlich ${ }^{1}$, \\ Peter Angele ${ }^{1,2}$ and Johannes Zellner ${ }^{1, *}$ \\ 1 Department of Trauma Surgery, University Medical Centre Regensburg; Franz Josef Strauss Allee 11, \\ 93053 Regensburg, Germany; felix.achatz@googlemail.com (F.P.A.); richard.kujat@ukr.de (R.K.); \\ christian.pfeifer@ukr.de (C.G.P.); matthias.koch@ukr.de (M.K.); michael.nerlich@ukr.de (M.N.); \\ peter.angele@ukr.de (P.A.) \\ 2 Sporthopaedicum Regensburg, Hildegard von Bingen Strasse 1, 93053 Regensburg, Germany \\ * Correspondence: johannes.zellner@ukr.de; Tel.: +49-941-944-6805; Fax: +49-941-944-6806
}

Academic Editors: C. Edi Tanase, Michael Nerlich and Arne Berner

Received: 30 January 2016; Accepted: 29 March 2016; Published: 7 April 2016

\begin{abstract}
A combination of mesenchymal stem cells (MSCs) and scaffolds seems to be a promising approach for meniscus repair. To facilitate the search for an appropriate scaffold material a reliable and objective in vitro testing system is essential. This paper introduces a new scoring for this purpose and analyzes a hyaluronic acid (HA) gelatin composite scaffold and a polyurethane scaffold in combination with MSCs for tissue engineering of meniscus. The pore quality and interconnectivity of pores of a HA gelatin composite scaffold and a polyurethane scaffold were analyzed by surface photography and Berliner-Blau-BSA-solution vacuum filling. Further the two scaffold materials were vacuum-filled with human MSCs and analyzed by histology and immunohistochemistry after 21 days in chondrogenic media to determine cell distribution and cell survival as well as proteoglycan production, collagen type I and II content. The polyurethane scaffold showed better results than the hyaluronic acid gelatin composite scaffold, with signs of central necrosis in the HA gelatin composite scaffolds. The polyurethane scaffold showed good porosity, excellent pore interconnectivity, good cell distribution and cell survival, as well as an extensive content of proteoglycans and collagen type II. The polyurethane scaffold seems to be a promising biomaterial for a mesenchymal stem cell-based tissue engineering approach for meniscal repair. The new score could be applied as a new standard for in vitro scaffold testing.
\end{abstract}

Keywords: meniscus; polyurethane scaffold; composite scaffold; hyaluronic acid; collagen; gelatin; chondrogenesis; human mesenchymal stem cells; biocompatibility

\section{Introduction}

Lesions of the meniscus are amongst the most frequent injuries in orthopedic surgery [1]. In many cases partial meniscectomy has to be performed due to the poor healing capacity of the avascular part of the meniscus [2]. This however predisposes for osteoarthritic changes of the affected knee joint [2-4]. Knee menisci are essential in providing joint stability [5], lubrication [6], proprioception [7], force transmission [8], and shock absorption [9]. Additionally, partial meniscectomy causes severe changes in the biomechanics of the knee joint that are directly proportional to the amount of lost tissue [10] resulting in drastically increased contact pressure to the surrounding cartilage [11]. Therefore, it is essential to restore as much meniscus substance as possible. While successful repair strategies for 
lesions in the vascular part of the meniscus have been developed, there is still no sufficient therapy for lesions in the avascular part [12]. Currently two scaffolds are used in clinic in a cell-free approach for meniscus repair: $\mathrm{CMI}^{\circledR}$, a collagen scaffold, and Actifit ${ }^{\circledR}$, a polyurethane scaffold. Both scaffolds have shown promising results [1,13-15], however, as of yet no large randomized studies with control groups have been published. Recently, mesenchymal stem cells have been a focus of attention in newly developed approaches for meniscus repair [15]. As these cells have both the potential to differentiate into fibro chondrocytes and the ability to secrete repair promoting growth factors they seem an ideal tool for meniscus repair [16]. Preclinical studies have already shown the repair potential of mesenchymal stem cells in combination with a scaffold in the treatment of relatively small tears and punch defects in the avascular zone of the meniscus [17-19]. A recent review article highlights the capability of cells to enhance meniscus repair, however, it remains unclear which biomaterial is best suited for this purpose [20]. With new scaffold materials evolving, costly animal experiments have to be conducted before putting them into clinical trials. To save time, resources and animals, a reliable in vitro testing system is needed to single out promising materials before going into in vivo experiments. The object of this paper is to thoroughly test two biomaterials for their suitability to be used in a mesenchymal stem cell based approach for tissue engineered meniscus. Both to rank our own results as well as to introduce a new standard for biomaterial testing we created a scoring system. We tested the polyurethane scaffold Actifit ${ }^{\circledR}$ that has already shown promising results in clinical trials [1], as well as a hyaluronic acid gelatin composite scaffold that has shown good results in several in vivo experiments [19].

\section{Materials and Methods}

\subsection{Production of Composite Scaffolds}

Hyaluronic acid gelatin composite scaffolds were produced as described elsewhere [21,22]. Briefly, the material contained $70 \%$ hyaluronic acid (commercially available product, Jaloskin ${ }^{\circledR}$, Fidia Advances Biopolymers, Abano Terme, Italy) and 30\% gelatin (hydrolyzed bovine collagen, Sigma, Seelze, Germany). To obtain a porous material solvent casting particulate leaching technique was applied. Both components were solved, mixed, and air dried after the addition of $\mathrm{NaCl}$-chrystals. Salt was washed out with water and the material was then dried in vacuum. Pore size was $350-450 \mu \mathrm{m}$. The product was cut in smaller parts and then sterilized with $25 \mathrm{kGy}$ beta rays (Beta-Gamma-Service GmbH, Saal, Germany).

\subsection{Polyurethane Scaffolds}

The commercially available polyurethane scaffold Actifit ${ }^{\circledR}$ (Orteq, London, UK) was used for this study. The product was cut in smaller parts and then sterilized with $25 \mathrm{kGy}$ beta rays (Beta-Gamma-Service GmbH, Saal, Germany).

\subsection{Macroscopic Assessment of Scaffold Pore Structure}

For each biomaterial a whole biomaterial meniscus was cut into $2 \mathrm{~mm}$ thick slices whose surfaces were subsequently photographed. Using highly-magnified and printed photographs, the quality the pore structure was assessed by two blinded and experienced scorers. Scorers conducted this by using the naked eye to get a quick and simple overview, enabling a semi-quantitative analysis.

\subsection{Interconnectivity of Scaffold Pores}

For each biomaterial two $2 \mathrm{~mm}$ thick slices were filled with a Berliner-Blau-BSA-solution containing $10 \%$ Berliner Blau and 10\% BSA in distilled water. Filling was conducted by vacuum as described below. Filled scaffolds were fixated overnight in phosphate buffer $0.1 \mathrm{M}$ with $4 \%$ paraformaldehyde and $1 \%$ glutaraldehyde and embedded in TissueTek ${ }^{\circledR}$ (Sakura Finetek Japan Co., Tokyo, Japan) the following day using liquid nitrogen. Blocks were cut in the cryotome and their 
surfaces were repeatedly photographed after each $100 \mu \mathrm{m}$ cut in order to create a representative series of images. The Berliner-Blau-BSA-solution was only found in pores that had indirect access to the surface of the scaffold and were, thus, interconnected. A qualitative assessment of the interconnectivity was conducted by two blinded and experienced scorers. Scorers used the naked eye to semi-quantitatively determine the percentage of interconnected pores, which is equivalent to the percentage of the scaffold area that shows the typical Berliner-Blau color.

\subsection{Isolation and Culture of Human Mesenchymal Stem Cells}

After approval by the local ethical committee and patients' informed consent, bone marrow-derived MSCs were acquired from patients with surgery that included harvest from the iliac crest.

Mononuclear cells were layered over the Ficoll-Paque (GE Healthcare Bio-Sciences, Marlborough, MA, USA) density-gradient. A heparinized syringe was used to aspirate the layer with MSCs, Dulbecco's modified Eagle's medium (DMEM), low glucose concentration (5\%), with 10\% fetal bovine serum, $1 \%$ penicillin, and $1 \%$ Hepes buffer was added and $2 \times 10^{6}$ nucleated cells were plated per T75 cell culture dish. The adherent cells expanded quickly and media was changed twice a week until reaching of $80 \%$ confluence.

\subsection{In Vitro Chondrogenesis}

Upon reaching $80 \%$ confluence mesenchymal stem cells were trypsinized, counted, washed, and re-suspended in a chemically-defined chondrogenic medium to final concentration of $2 \times 10^{4}$ cells $/ \mu \mathrm{L}$. As previously described by Angele et al. [23] chondrogenic media contained DMEM (high glucose), $200 \mu \mathrm{M}$ ascorbic acid-2 phosphate, 1\% insulin-transferrin-sodium selenite media supplement (ITS) (both from Sigma, Taufkirchen, Germany), $1 \mathrm{mM}$ pyruvate, $100 \mathrm{nM}$ dexamethasone, and $10 \mathrm{ng} / \mathrm{mL}$ transforming growth factor 1 1(TGFß1) (R and D systems, Wiesbaden, Germany).

Cylindric (diameter: $5 \mathrm{~mm}$, height: $2 \mathrm{~mm}$ ) scaffold parts were then loaded with $50 \mu \mathrm{L}$ of the cell suspension $\left(1 \times 10^{6}\right.$ cells) per scaffold part. From each biomaterial, 6-12 scaffolds were loaded. Loading of the scaffolds was achieved using a rotary valve vacuum pump (Vacuubrand $\mathrm{GmbH}$, Wertheim, Germany). Both scaffold and cell suspension were placed into cylindrical tubes. Vacuum was then applied for $10 \mathrm{~s}$, followed by a brief ventilation. This was repeated 10 times. The strength of the applied vacuum was adjusted manually to an extent that showed moderate foam generation in the media.

The loaded scaffolds were then incubated at $37^{\circ} \mathrm{C}$ for $1 \mathrm{~h}$ and five scaffolds of each biomaterial were then kept in chondrogenic media for 21 days under normoxic conditions, media was changed three times a week. Per biomaterial, one scaffold was fixated on the next day, serving as a loading control.

\subsection{Histology}

The scaffolds from the in vitro differentiation were fixed in a $1 \mathrm{M}$ phosphate buffer solution containing 4\% paraformaldehyde, embedded in Tissue-Tek OCT (Sakura Finetek, Tokyo, Japan) and frozen in liquid nitrogen. All samples were cut in $10 \mu \mathrm{m}$ sections and every 10 th of them was stained with dimethylmethylen blue (DMMB). Two blinded scorers analyzed the sections according to the proposed scoring system. This was conducted by the naked eye to assess semi-quantitative differences. Both scorers were experienced in analyzing histological cartilage sections.

To evaluate the cell viability we searched for secure histological signs of cell death, such as blurred cell nucleus borders and loss of adherence. Cell distribution was assessed by comparing the number of cell-populated pores to the number of cell-free pores. The content of proteoglycan was measured by determining the percentage of metachromatic extracellular matrix in scaffold pores. 


\subsection{Immunohistochemistry}

Sections were washed followed by a 15 min digestion with $0.1 \%$ pepsin at $\mathrm{pH} 3.5$ for a facilitated antibody access to the target epitopes. Type I and II collagen were immunolocalized by the immunoperoxidase $\mathrm{ABC}$ technique (Vector, Burlingame, CA, USA). As primary antibodies anti-collagen II (clone II-4C11; Calbiochem Merck, Schwalbach, Germany) and monoclonal CD31 mouse anti-rabbit antibodies (clone JC-70A IgG1 light chain type kappa; Abcam, Cambridge, UK) were used. After staining with biotin conjugated polyclonal goat anti mouse IgG secondary antibody (Jackson, West Grove, PA, USA), positive signals were visualized by nickel- and cobalt-enhanced 3,3'-diaminobenzidine (DAB). Two blinded scorers analyzed the sections semi-quantitatively according to the proposed scoring system. Percentage of content of collagen I or collagen II was determined by comparing DMMB stained slides with immunohistochemically stained slides.

\subsection{Score}

To our knowledge as of yet there has not been described a score for standardized in vitro analysis and comparison of newly developed biomaterial for stem cell-based meniscus repair. Therefore, we propose the following score.

For scoring item 1, magnified photographs of the surface of the biomaterial slices were analyzed. Berliner-Blau-solution filled biomaterial slices were analyzed for scoring item 2.

For scoring items 3-7, five to ten scaffolds per biomaterial were analyzed after being filled with MSCs and 21 days of differentiation in chondrogenic media.

Further details about assessing the scoring values' different parameters are outlined in the above paragraphs.

Each of this scaffolds was assessed on its own for each scoring item and the average scoring value was noted as a whole number value in the score. Scoring values are displayed in Table 1.

Table 1. Scoring system for analysis of biomaterials used for meniscal substitution or tissue engineering of the meniscus.

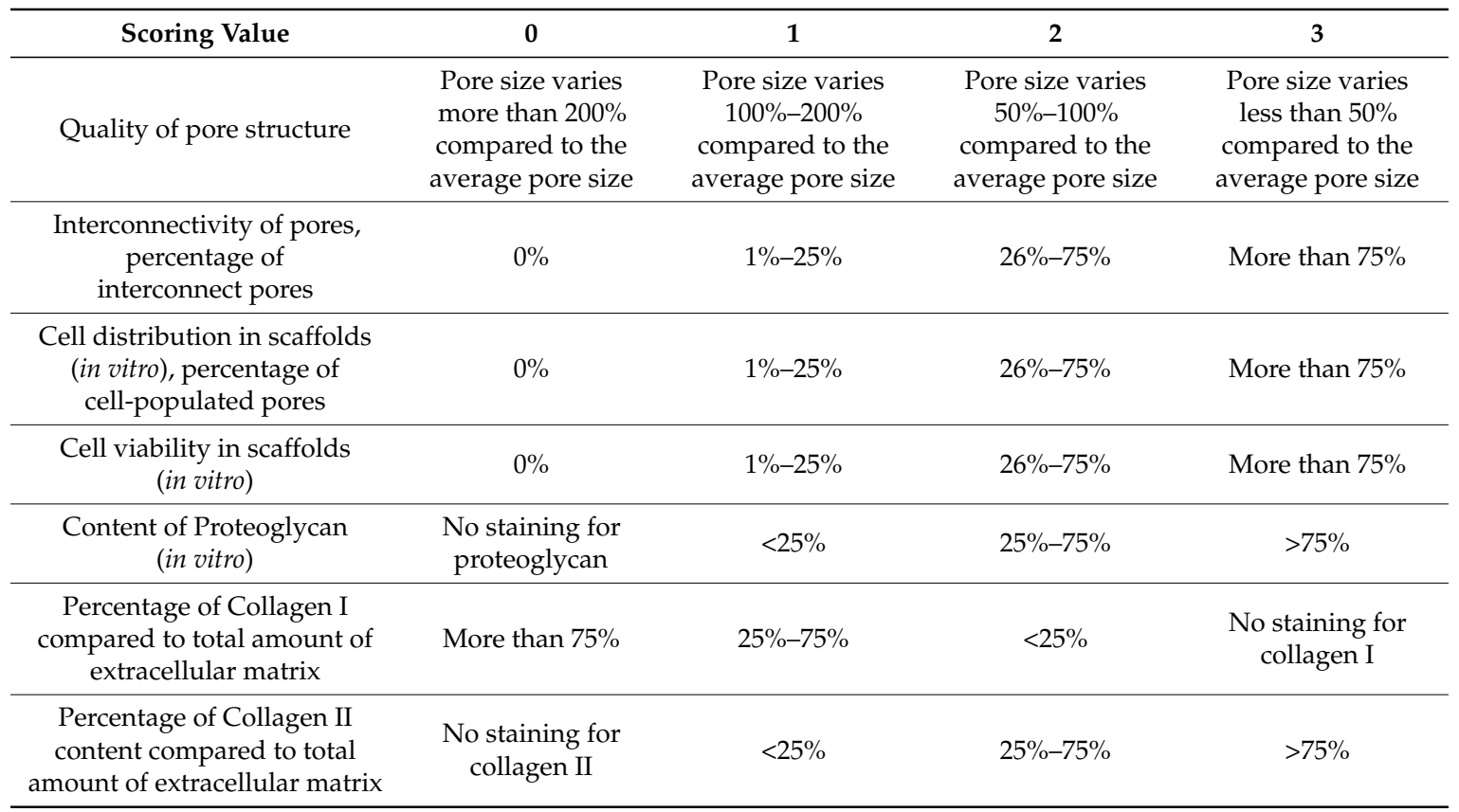

That way seven individual scoring subgroups were formed, each received a scoring value ranging from 0 (bad) to 3 (ideal). The values of these items were summed up, consequently reaching a combined score from 0 (material unsuitable for meniscus repair) to 21 (promising material for MSC-based 
meniscus repair). Two experienced blinded scorers conducted the data collection. A high internal consistency has been attributed to this scoring system by a statistician from the Center of Clinical Studies of the University of Regensburg, thus making it legitimate to sum up the single item scores.

\subsection{Statistical Analysis}

To determine whether data followed a Gaussian distribution a Kolmogorov-Smirnov test was conducted. For comparison of non-normal distributed data the Mann-Whitney U-test was used. A probability value of less than 0.05 was set as the level of statistical significance for all evaluations.

\section{Results}

We conducted a thorough test of two biomaterials, one being a hyaluronic acid gelatin composite scaffold developed in our own working group, the other one being the commercially available polyurethane based product Actifit ${ }^{\circledR}$ which is already in clinical use for cell-free meniscal replacement after subtotal loss of meniscus substance.

\subsection{Macroscopical Assessment of Scaffold Pore Structure}

The biomaterials were cut into $2 \mathrm{~mm}$ thick slices to assess the quality of the porosity. Both the hyaluronic acid gelatin composite scaffold as well as the Actifit ${ }^{\circledR}$ scaffold showed an even distribution of pores that varied less than $50 \%$ in size (Figures 1 and 2).

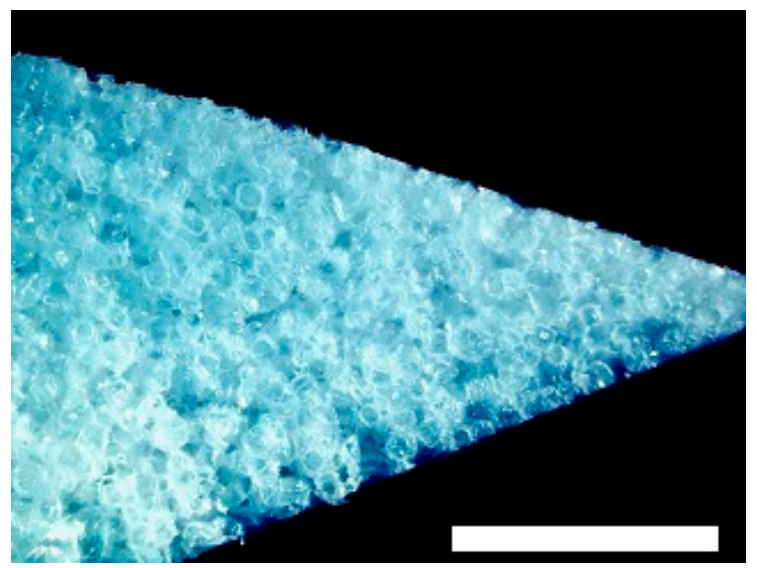

Figure 1. Macroscopic enhanced image of a hyaluronic acid gelatin composite scaffold. Scale bar $=1 \mathrm{~mm}$.

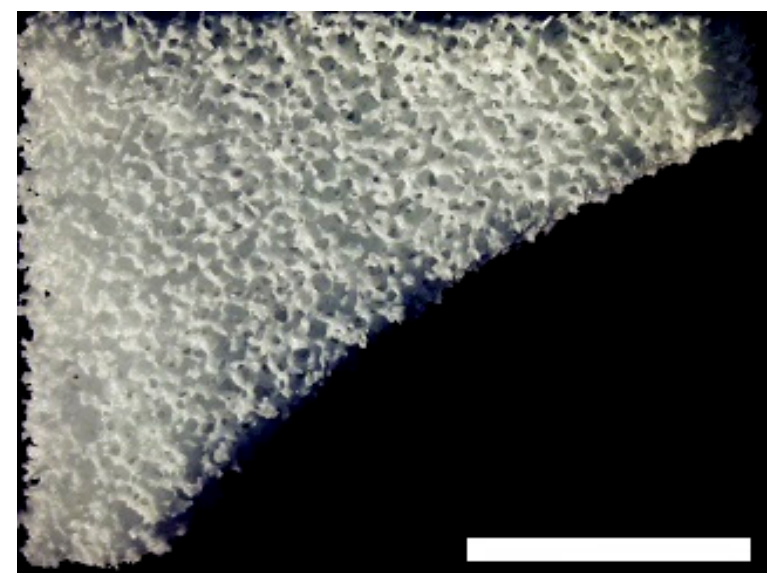

Figure 2. Macroscopic enhanced image of an Actifit ${ }^{\circledR}$ scaffold. Scale bar $=1 \mathrm{~mm}$. 


\subsection{Interconnectivity of Scaffold Pores}

To assess the interconnectivity of the scaffolds' pores the scaffolds were filled with a Berliner-Blau-BSA-solution that could only penetrate into interconnected pores. The hyaluronic acid gelatin composite scaffold showed a very strong interconnectivity of pores with almost no pores remaining unfilled. The Actifit ${ }^{\circledR}$ scaffold showed good interconnectivity of pores in the center of the scaffold, however, many pores in the scaffold's periphery remained unfilled (Figures 3 and 4).

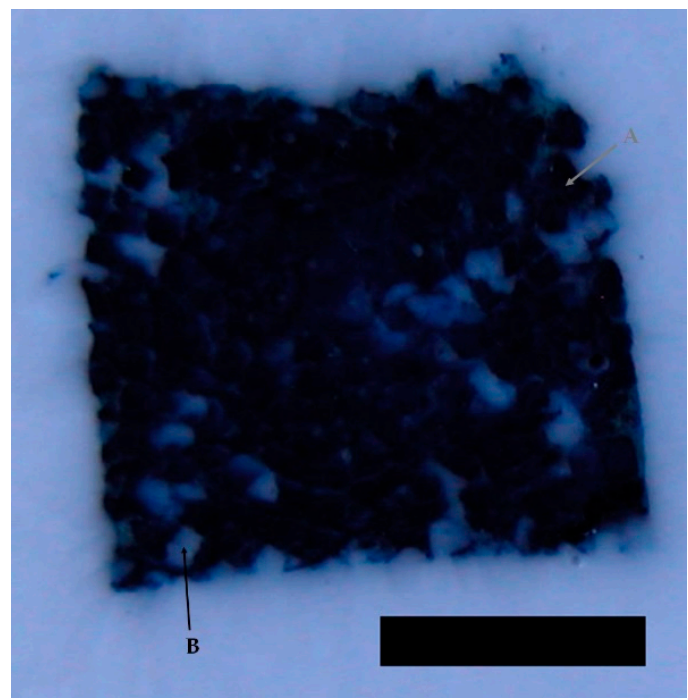

Figure 3. Illustration of pore interconnectivity in a hyaluronic acid gelatin composite scaffold. Black areas represent accessible pores whereas white areas signify secluded pores. Arrow A points to an interconnected, accessible pore. Arrow B points to a non-interconnected, secluded pore. Most of the scaffold's area is shows a black color, thus proving excellent pore interconnectivity. Magnification bar $=1 \mathrm{~mm}$.

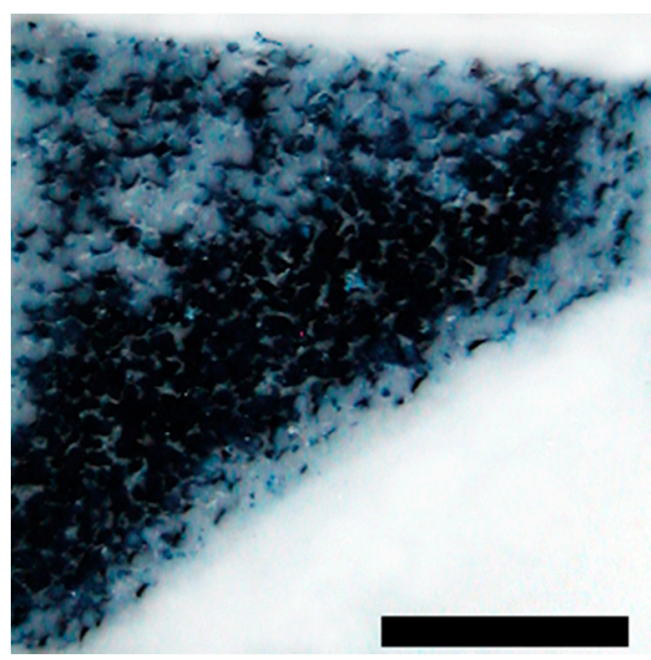

Figure 4. Illustration of pore interconnectivity in an Actifit ${ }^{\circledR}$ scaffold. Black areas represent accessible pores whereas white areas signify secluded pores. A major part of the scaffold's area is shows a black color, thus proving good pore interconnectivity Magnification bar $=1 \mathrm{~mm}$. 


\subsection{In Vitro Chondrogenesis}

To analyze the biocompatibility of the materials an in vitro experiment was conducted. Per biomaterial six scaffold cylinders, $2 \mathrm{~mm}$ in height, and $5 \mathrm{~mm}$ in diameter were filled with human MSCs and kept in chondrogenic media for 21 days.

Upon harvest the hyaluronic acid gelatin composite scaffolds appeared instable, sensitive to touch with obvious signs of degradation. DMMB staining showed an initially excellent cell distribution with more than $75 \%$ of pores being populated by cells. However, after 21 days the survival rate of cells was unsatisfying, with an approximate average of $50 \%$ percent of cells showing signs of necrosis, especially in the central parts of the scaffolds. Accordingly, only the peripheral pores of the scaffolds were extensively filled with proteoglycans, whereas the central parts remained fairly empty. Figures 5 and 6 show representative DMMB-stained slices.

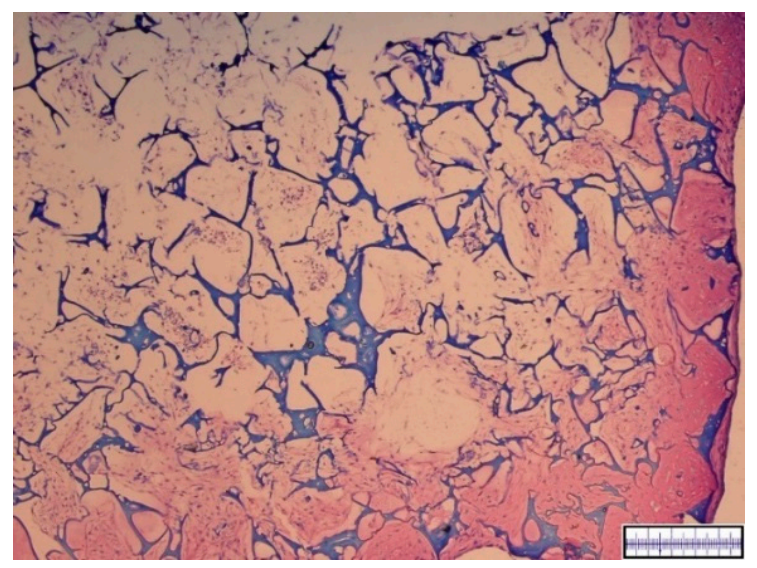

Figure 5. Representative histological slide of a hyaluronic acid gelatin composite scaffold after 21 days of in vitro chondrogenesis with visible central necrosis. DMMB staining. Proteoglycan-rich extracellular matrix appears red, scaffold parts appear blue. Magnification bar $=500 \mu \mathrm{m}$.

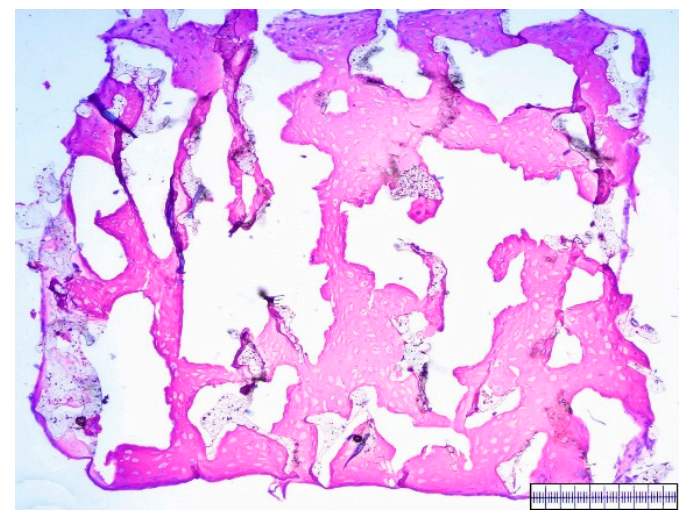

Figure 6. Representative histological slide of an Actifit ${ }^{\circledR}$ scaffold after 21 days of in vitro chondrogenesis. DMMB staining. Proteoglycan-rich extracellular matrix appears red, scaffold parts appear grey and porous. Magnification bar $=500 \mu \mathrm{m}$.

Immunohistochemistry showed high levels of both collagen I and II in peripheral parts and almost no collagen I or II in the central parts of the scaffolds.

The Actifit ${ }^{\circledR}$ scaffolds appeared stable upon harvest with no obvious signs of degradation. Initial cell distribution was excellent with more than $75 \%$ of pores being cell-populated. No signs of necrosis were observed. Throughout the whole scaffolds extensive production of proteoglycans was noted. Immunohistochemistry showed high levels of collagen type II and moderate levels of collagen type 
I content. Figures 7 and 8 show representatives slices with collagen type I immunohistochemistry. Collagen type II immunohistochemistry is displayed in Figures 9 and 10.

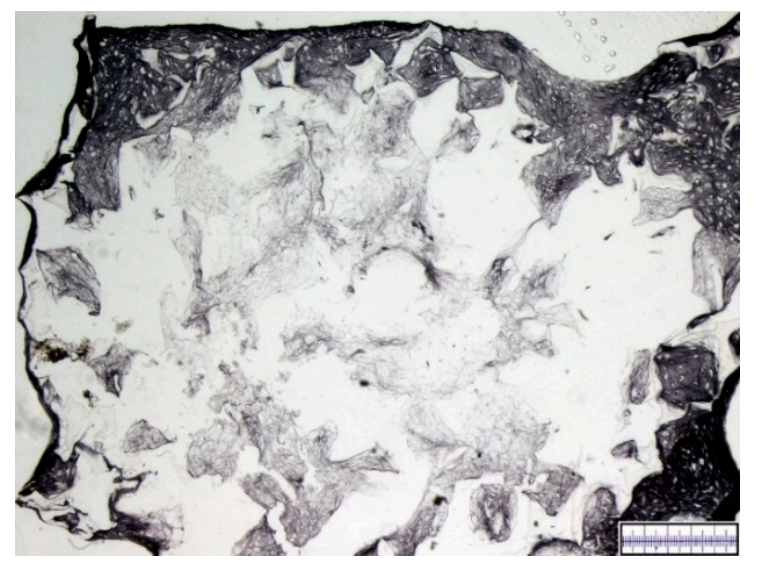

Figure 7. Representative slide of a hyaluronic acid gelatin composite scaffold after 21 days of in vitro chondrogenesis. Collagen type I immunohistochemistry. Collagen type I-rich areas appear black. Magnification bar $=500 \mu \mathrm{m}$.

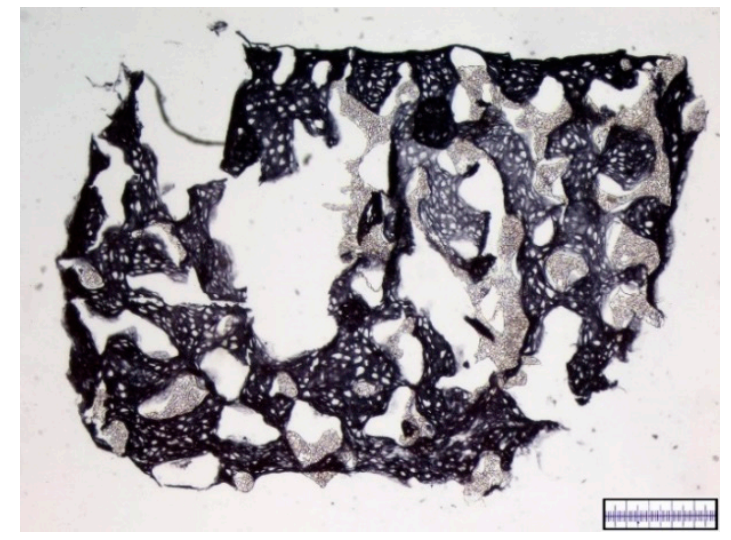

Figure 8. Representative slide of an Actifit ${ }^{\circledR}$ scaffold after 21 days of in vitro chondrogenesis. Collagen type I immunohistochemistry. Collagen type I-rich areas appear black. Magnification bar $=500 \mu \mathrm{m}$.

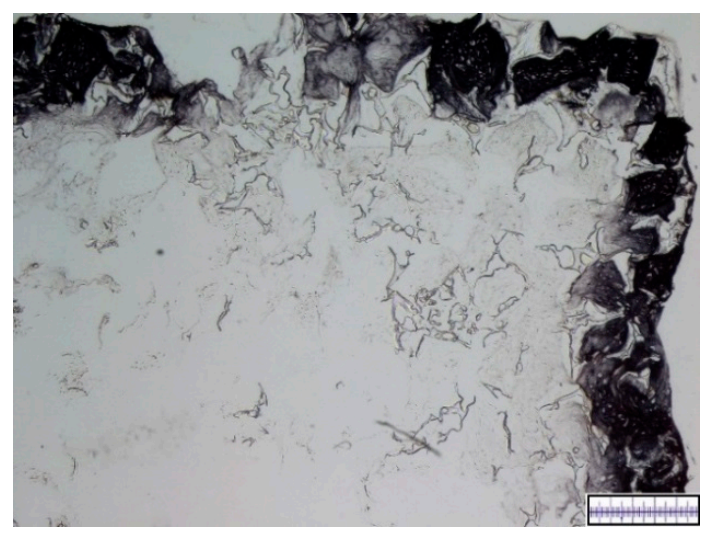

Figure 9. Representative slide of a hyaluronic acid gelatin composite scaffold after 21 days of in vitro chondrogenesis. Collagen type II immunohistochemistry. Collagen type II-rich areas appear black. Magnification bar $=500 \mu \mathrm{m}$. 


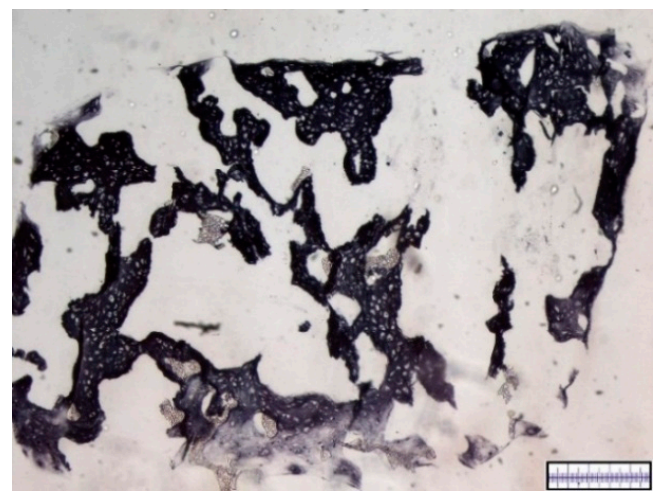

Figure 10. Representative slide of an Actifit ${ }^{\circledR}$ scaffold after 21 days of in vitro chondrogenesis. Collagen type II immunohistochemistry. Collagen type II-rich areas appear black. Magnification bar $=500 \mu \mathrm{m}$.

\subsection{Scoring}

In our scoring system scaffolds receive an overall score ranging from 0 (=not suitable) to 21 (=very promising). Both hyaluronic acid gelatin composite scaffold and Actifit ${ }^{\circledR}$ received promising results, however, Actifit ${ }^{\circledR}$ still obtained a clearly higher total score of 19 points compared to the hyaluronic acid gelatin composite scaffold's 15 points (Figure 11).

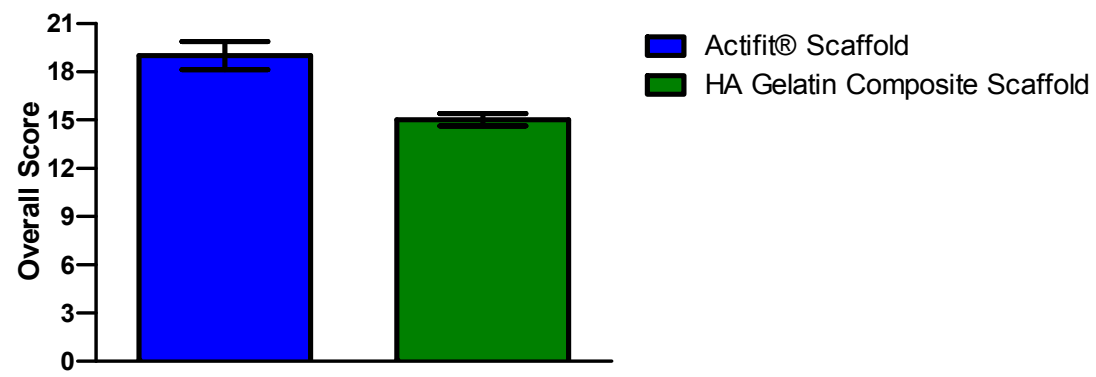

Figure 11. Overall Scoring Results of the different scaffolds. Error bars indicate $95 \%$ confidence interval.

The hyaluronic acid gelatin composite scaffold received statistically significant less points $(p<0.05)$ for cell survival compared to Actifit ${ }^{\circledR}$, because necrosis took place in the central parts of the hyaluronic acid gelatin composite scaffolds. The diminished number of vital cells consequently produced fewer proteoglycans and collagen II, thus leading to further point losses in these categories. The scoring results for cell viability are displayed in Figure 12.

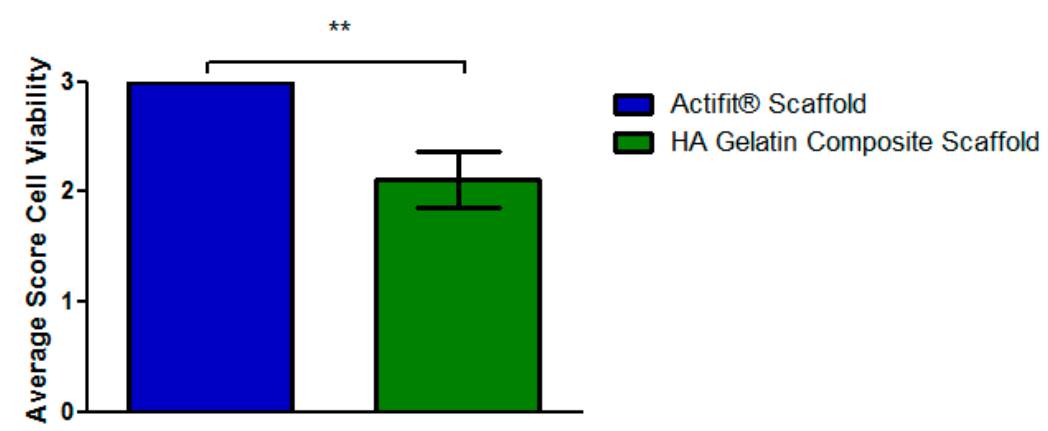

Figure 12. Average scoring results of the different scaffolds for single score item viability of cells. Error bars indicating 95\% confidence interval. Scoring item was assessed in a semi-quantitative manner. Cell viability was statistically significant better (Mann-Whitney-U test, ${ }^{* *}=p<0.05$ ) in the Actifit ${ }^{\circledR}$ scaffolds $^{*}$ compared to the HA (hyaluronic acid) gelatin composite scaffolds. 


\section{Discussion}

The main purpose of this paper is to introduce a new scoring system that can be universally applied for in vitro testing of biomaterials for scaffold-based cell-enhanced meniscus repair. To demonstrate the execution and validity of our score we used it to compare two scaffolds that have been previously used both in an in vitro setting, an in vivo setting in an animal model $[15,18,19,24]$. One of the scaffolds is already clinically used in a cell-free approach [1].

We thoroughly analyzed two biomaterial scaffolds regarding their capacity for mesenchymal stem cell-based meniscus repair: the polyurethane scaffold Actifit ${ }^{\circledR}$ and a hyaluronic acid gelatin composite scaffold developed in our own working group. To objectify our results as well as to facilitate and standardize further testing we introduced a new point-based scoring system for the in vitro testing of biomaterial for meniscus repair.

In our test both scaffolds showed good results; however, Actifit ${ }^{\circledR}$ received a clearly better overall score. The hyaluronic acid gelatin composite scaffold showed excellent porosity, however, cell survival was limited with necrosis taking place in the central parts of the scaffolds. Consequently less proteoglycans and collagens were produced. Actifit ${ }^{\circledR}$ received excellent results throughout our test, this seems to support the argument that this scaffold should be further investigated in in vivo experiments and clinical trials.

In existing clinical trials $[1,15,25]$ as well as in in vivo experiments $[26,27]$ Actifit ${ }^{\circledR}$ showed good results with statistically significant improvements in clinical outcome as well as improved macroscopic and histologic meniscus healing. The hyaluronic acid gelatin composite scaffold showed promising results in several in vivo studies $[18,19,23]$. These good results of both scaffolds in in vivo experiments and clinical trials are concordant with the good results these scaffolds received in our in vitro test. This seems to prove the assumption that our new score can be a reliable tool to determine which biomaterials are worth being further tested in in vivo experiments and subsequent clinical trials. Using our new in vitro testing system research resources could be saved by saving money, time and animal lives. Furthermore our score can be used to standardize biomaterial testing, thus making it possible to objectively compare results amongst different working groups.

As described in the next paragraphs, our score incorporates the assessment of the most important qualities of scaffolds for meniscus repair. According to several authors [28,29] scaffolds should have the following qualities: biocompatibility, open pores to enable tissue ingrowth and properties for cell adhesion.

Especially the quality of porosity is an essential feature for successful tissue engineering of the meniscus with mesenchymal stem cell-filled scaffolds [30].

Therefore, our scoring system contains three single scoring items that are directly or indirectly connected with the quality of the scaffold porosity: the quality of pore structure, the interconnectivity of pores and the cell distribution in the scaffolds.

As mentioned above, biocompatibility is a vital feature for a successful biomaterial. Our testing system thoroughly assesses the biocompatibility of the scaffolds with the scoring items of the in vitro experiment: viability of cells and production of proteoglycans.

Furthermore it is important for the cells inside the scaffolds to not merely produce scar tissue but to produce mechanically stable meniscus-like tissue. The dry mass of the human meniscus mainly consists of collagen [31] and our chondrogenesis model is specifically set to enable production of collagen II. Consequently, our score rewards high contents of collagen type II as this also shows the successful differentiation of the MSCs. In contrast, collagen type I production rather hints to undifferentiated scar tissue, which is why a low content of collagen type I is rewarded with a high score in our testing system.

A recent review article gives an overview about the currently used scoring systems for meniscus repair [32]. While none of these scoring systems are intended for the in vitro evaluation of biomaterial, they nonetheless frequently analyze certain key tissue characteristics that are also assessed in our score. These central tissue characteristics include cellularity, collagen formation, and proteoglycan content. 
The aspect of scaffold porosity has mostly been neglected in the described scoring systems. However, we consider porosity to be a central aspect for scaffolds and, therefore, made it a big part of our score.

As demonstrated, our score covers the most important properties of a good biomaterial scaffold for meniscus repair and therefore qualifies as a highly effective tool with a very accurate prediction value for the assessment of new biomaterials. Our score assesses differences in key characteristics that are vital for any type of scaffold; consequently, our score can be applied for testing any kind of biomaterial that is intended for cell-enhanced meniscus repair. Our scoring system offers a thorough, but easily reproducible, seven step evaluation that can help investigators to both objectify their results and to compare the qualities of different biomaterials.

In biomaterial research a variety of animal types has been used, amongst others: rabbits, dogs, and sheep. As our score relies on standardized in vitro conditions we eliminate the variability of results that is involved when using different types of animals for in vivo studies.

Mesenchymal stem cells have been a focus of research as a source for tissue engineering, which is why we used mesenchymal stem cells in our experiments. However, our scoring system could also be used for a combination of scaffold with different cell types.

There are some limitations to our study, which we purposely tolerate for different reasons. While biomechanics are an essential property of any biomaterial [33] our score does not examine it. Biomechanics and biocompatibility should be assessed separately, as it facilitates identification of parameters that have to be adjusted. Furthermore, a thorough test regime for the functional and biomechanical analysis of scaffolds has already been described by Maher et al [26]. This test regime can easily be combined with our scoring system, thus creating a complete evaluation of a biomaterial. Another limitation of our study might be the relatively low-key use of quantification, software, and special viability staining, as well as the relying on naked eye assessment. However, we wanted to create a simple score that can quickly and easily be applied by any investigator without having to purchase expensive dyes or software. Experienced meniscus investigators are capable of a reliable and objective naked eye examination that gives valuable qualitative information. Our score possesses the advantage to function not only with a relatively simple approach like presented in this study, but also with a more quantified approach, as single scoring items could also be assessed with quantification software or assays, if this is desired. For these reasons and despite its limitations our scoring system presents a valuable novel tool for the evaluation of scaffolds. Our score gives a quick overview whether a newly developed bio material is worth to proceed to further research steps for example in an in vivo setting.

Given the good results the Actifit ${ }^{\circledR}$ scaffold reached in our experiments it qualifies for mesenchymal stem cell-based meniscus repair and should be further investigated in in vivo experiments and clinical trials.

As mentioned above, cell-free scaffolds are currently used in clinics with promising results, however, this approach could possibly be further enhanced by the addition of mesenchymal stem cells. The ideal cell for cell-based meniscus repair should be autologous, obtainable in sufficient numbers in a minimal-invasive procedure and it has to possess the ability to be expanded in tissue culture and to produce stable fibrocartilaginous extracellular matrix [34]. These qualities are met by MSCs: they are easily obtainable via bone marrow puncture [35], can be expanded in tissue culture without losing their stem cell characteristics [36], and have shown the ability to produce fibrocartilaginous extracellular matrix [18].

Several studies have shown a statistically significant benefit that resulted by loading a scaffold with MSCs compared to cell-free scaffolds $[18,19]$. This benefit seems to originate from a dual role of the MSCs in meniscus repair [17]. Firstly, MSCs could directly heal meniscus lesions, as they can differentiate into fibro chondrocytes [37]. Secondly, MSCs could indirectly enhance meniscus healing via secretion of bioactive substances [38] that promote self-healing. Furthermore, MSCs possess immunoregulatory properties and could, thus, prevent tissue destruction and scar formation in injured tissue [38]. Consequently, the use of MSCs to enhance scaffold-based meniscus repair seems to be a promising approach. 


\section{Conclusions}

The new score we developed could be applied as a new standard for in vitro scaffold testing of different biomaterials and, thus, save precious financial resources, as well as research animals and time.

The polyurethane scaffold showed excellent results in our in vitro test and seems to be a promising biomaterial for tissue engineering with MSCs. In vivo studies with a mesenchymal stem cell-filled Actifit $^{\circledR}$ scaffold will determine whether this approach can be applied in clinics.

Acknowledgments: We want to highly acknowledge technical support of Daniela Drenkard. Further we want to thank Florian Zeman from the Center of clinical studies of the University of Regensburg for the evaluation of our score. This study was funded by intramural funding of the Clinic and Policlinic for Trauma Surgery, University Medical Center Regensburg and by Orteq.

Author Contributions: All authors contributed to the study design, data analysis, and discussion, as well as to the writing and editing of the manuscript. Study conception and design: Johannes Zellner, Richard Kujat, Michael Nerlich and Peter Angele. Scaffold production, technical advice: Richard Kujat, Christian G. Pfeifer, Felix P. Achatz and Matthias Koch. Data analysis and discussion: Felix P. Achatz., Christian G. Pfeifer, Matthias Koch, Michael Nerlich, Peter Angele and Johannes Zellner. Manuscript writing, editing, and revision: Felix P. Achatz, Johannes Zellner and Peter Angele.

Conflicts of Interest: The authors declare no conflict of interest. Parts of the project (Actifit ${ }^{\circledR}$ biomaterial supply) were supported by Orteq. The funding sponsors had no role in the design of study; in the collection, analysis or interpretation of data; in the writing of the manuscript, and in the decision to publish the results.

\section{Abbreviations}

The following abbreviations are used in this manuscript:

BSA

DMMB

bovine albumin solution

MSCs

dimethylemethylene blue

HA mesenchymal stem cells hyaluronic acid

TGF-beta transforming growth factor beta

\section{References}

1. Verdonk, P.; Beaufils, P.; Bellemans, J.; Djian, P.; Heinrichs, E.-L.; Huysse, W.; Laprell, H.; Siebold, R.; Verdonk, R.; Colombet, P.; et al. Successful Treatment of Painful Irreparable Partial Meniscal Defects with a Polyurethane Scaffold: Two-Year Safety and Clinical Outcomes. Am. J. Sports Med. 2012, 40, 844-853. [CrossRef] [PubMed]

2. Brindle, T.; Nyland, J.; Johnson, D.L. The meniscus: Review of basic principles with application to surgery and rehabilitation. J. Athl. Train 2001, 36, 160-169. [PubMed]

3. Petty, C.A.; Lubowitz, J.H. Does arthroscopic partial meniscectomy result in knee osteoarthritis? A systematic review with a minimum of 8 years' follow-up. Arthroscopy 2011, 27, 419-424. [CrossRef] [PubMed]

4. Liu, C.; Toma, I.C.; Mastrogiacomo, M.; Krettek, C.; Lewinski, G.; von Jagodzinski, M. Meniscus reconstruction: Today's achievements and premises for the future. Arch. Orthop. Trauma. Surg. 2013, 133, 95-109. [CrossRef] [PubMed]

5. Levy, I.M.; Torzilli, P.A.; Gould, J.D.; Warren, R.F. The effect of lateral meniscectomy on motion of the knee. J. Bone Joint Surg. Am. 1989, 71, 401-406. [PubMed]

6. Renstrom, P.; Johnson, R.J. Anatomy and biomechanics of the menisci. Clin. Sports Med. 1990, 9, 523-538. [PubMed]

7. Akgun, U.; Kocaoglu, B.; Orhan, E.K.; Baslo, M.B.; Karahan, M. Possible reflex pathway between medial meniscus and semimembranosus muscle: An experimental study in rabbits. Knee Surg. Sports Traumatol. Arthr. 2008, 16, 809-814. [CrossRef] [PubMed]

8. McDermott, I.D.; Amis, A.A. The consequences of Meniscectomy. Bone Joint Surg. Br. 2006, 88, 1549-1556. [CrossRef] [PubMed]

9. Kurosawa, H.; Fukubayashi, T.; Nakajima, H. Load-bearing mode of the knee joint: Physical behavior of the knee joint with or without menisci. Clin. Orthop. Relat. Res. 1980, 149, 283-290. [CrossRef] [PubMed] 
10. Ahmed, A.M.; Burke, D.L. In-vitro measurement of static pressure distribution in synovial joints-Part I: Tibial surface of the knee. J. Biomech. Eng. 1983, 105, 216-225. [CrossRef] [PubMed]

11. Vrancken, A.C.T.; Buma, P.; Tienen, T.G. Synthetic meniscus replacement: A review. Int. Orthop. 2013, 37, 291-299. [CrossRef] [PubMed]

12. Kimura, M.; Shirakura, K.; Hasegawa, A.; Kobuna, Y.; Niijima, M. Second look arthroscopy after meniscal repair: Factors affecting the healing rate. Clin. Orthop. Relat. Res. 1995, 314, 185-191. [CrossRef] [PubMed]

13. Rodkey, W.G.; de Haven, K.E.; Montgomery, W.H.; Baker, C.L.; Hormel, S.E.; Steadman, J.R.; Cole, B.J.; Briggs, K.K. Comparison of the collagen meniscus implant with partial meniscectomy: A prospective randomized trial. J. Bone Joint Surg. Am. 2008, 90, 1413-1426. [CrossRef] [PubMed]

14. Abrams, G.D.; Frank, R.M.; Gupta, A.K.; Harris, J.D.; McCormick, F.M.; Cole, B.J. Trends in Meniscus Repair and Meniscectomy in the United States, 2005-2011. Am. J. Sports Med. 2013, 41, 2333-2339. [CrossRef] [PubMed]

15. Efe, T.; Getgood, A.; Schofer, M.D.; Fuchs-Winkelmann, S.; Mann, D.; Paletta, J.R.J.; Heyse, T.J. The safety and short-term efficacy of a novel polyurethane meniscal scaffold for the treatment of segmental medial meniscus deficiency. Knee Surg. Sports Traumatol. Arthrosc. 2012, 20, 1822-1830. [CrossRef] [PubMed]

16. Angele, P.; Kujat, R.; Koch, M.; Zellner, J. Role of mesenchymal stem cells in meniscal repair. J. Exp. Ortop. 2014, 1. [CrossRef] [PubMed]

17. Caplan, A.I.; Dennis, J.E. Mesenchymal stem cells as trophic mediators. J. Cell. Biochem. 2006, 98, 1076-1084. [CrossRef] [PubMed]

18. Zellner, J.; Hierl, K.; Mueller, M.; Pfeifer, C.; Berner, A.; Dienstknecht, T.; Krutsch, W.; Geis, S.; Gehmert, S.; Kujat, R.; et al. Stem cell-based tissue-engineering for treatment of meniscal tears in the avascular zone. J. Biomed. Mater. Res 2013, 101, 1133-1142. [CrossRef] [PubMed]

19. Zellner, J.; Mueller, M.; Berner, A.; Dienstknecht, T.; Kujat, R.; Nerlich, M.; Hennemann, B.; Koller, M.; Prantl, L.; Angele, M.; et al. Role of mesenchymal stem cells in tissue engineering of meniscus. J. Biomed. Mater. Res. 2010, 94, 1150-1161. [CrossRef] [PubMed]

20. Di Matteo, B.; Perdisa, F.; Gostynska, N.; Kon, E.; Filardo, G.; Marcacci, M. Meniscal Scaffolds-Preclinical Evidence to Support their Use: A Systematic Review. Open Orthop. J. 2015, 9, 143-156. [CrossRef] [PubMed]

21. Zellner, J. Tissue Engineering mit mesenchymalen Stammzellen und Hyaluronsäure-Gelatine Kompositmatrices zur Reparatur avaskulärer Meniskusläsionen. Ph.D. Thesis, University Regensburg, Regensburg, Germany, 2006.

22. Angele, P.; Kujat, R.; Nerlich, M.; Yoo, J.; Goldberg, V.; Johnstone, B. Engineering of osteochondral tissue with bone marrow mesenchymal progenitor cells in a derivatized hyaluronan-gelatin composite sponge. Tissue Eng. 1999, 5, 545-554. [CrossRef] [PubMed]

23. Angele, P.; Johnstone, B.; Kujat, R.; Zellner, J.; Nerlich, M.; Goldberg, V.; Yoo, J. Stem cell based tissue engineering for meniscus repair. J. Biomed. Mater. Res. 2008, 85, 445-455. [CrossRef] [PubMed]

24. Welsing, R.T.C.; van Tienen, T.G.; Ramrattan, N.; Heijkants, R.; Schouten, A.J.; Veth, R.P.H.; Buma, P. Effect on tissue differentiation and articular cartilage degradation of a polymer meniscus implant: A 2-year follow-up study in dogs. Am. J. Sports Med. 2008, 36, 1978-1989. [CrossRef] [PubMed]

25. Bouyarmane, H.; Beaufils, P.; Pujol, N.; Bellemans, J.; Roberts, S.; Spalding, T.; Zaffagnini, S.; Marcacci, M.; Verdonk, P.; Womack, M.; et al. Polyurethane scaffold in lateral meniscus segmental defects: Clinical outcomes at 24 months follow-up. Orthop. Traumatol. Surg. Res. 2014, 100, 153-157. [CrossRef] [PubMed]

26. Maher, S.A.; Rodeo, S.A.; Potter, H.G.; Bonassar, L.J.; Wright, T.M.; Warren, R.F. A pre-clinical test platform for the functional evaluation of scaffolds for musculoskeletal defects: The meniscus. HSS J. 2011, 7, 157-163. [CrossRef] [PubMed]

27. Verdonk, R.; Espregueira-Mendes, J.; Monllau, J.C. Meniscal Transplantation; Springer: Heidelberg, NY, USA, 2013.

28. Stone, K.R.; Steadman, J.R.; Rodkey, W.G.; Li, S.T. Regeneration of meniscal cartilage with use of a collagen scaffold: Analysis of preliminary data. J. Bone Joint Surg. Am. 1997, 79, 1770-1777. [PubMed]

29. Freed, L.E.; Vunjak-Novakovic, G.; Biron, R.J.; Eagles, D.B.; Lesnoy, D.C.; Barlow, S.K.; Langer, R. Biodegradable polymer scaffolds for tissue engineering. Biotechnology 1994, 12, 689-693. [CrossRef] [PubMed]

30. Matsiko, A.; Gleeson, J.P.; O'Brien, F.J. Scaffold mean pore size influences mesenchymal stem cell chondrogenic differentiation and matrix deposition. Tissue Eng. 2015, 21, 486-497. [CrossRef] [PubMed] 
31. Makris, E.A.; Hadidi, P.; Athanasiou, K.A. The knee meniscus: Structure-function, pathophysiology, current repair techniques, and prospects for regeneration. Biomaterials 2011, 32, 7411-7431. [CrossRef] [PubMed]

32. Longo, U.G.; Loppini, M.; Romeo, G.; Maffulli, N.; Denaro, V. Histological scoring systems for tissue-engineered, ex vivo and degenerative meniscus. Knee Surg. Sports Traumatol. Arthrosc. 2013, 21, 1569-1576. [CrossRef] [PubMed]

33. Shemesh, M.; Asher, R.; Zylberberg, E.; Guilak, F.; Linder-Ganz, E.; Elsner, J.J. Viscoelastic properties of a synthetic meniscus implant. J. Mech. Behav. Biomed. Mater. 2014, 29, 42-55. [CrossRef] [PubMed]

34. Hoben, G.M.; Athanasiou, K.A. Meniscal repair with fibrocartilage engineering. Sports Med. Arthrosc. 2006, 14, 129-137. [CrossRef] [PubMed]

35. Hernigou, P.; Desroches, A.; Queinnec, S.; Flouzat, L.; Charles, H.; Poignard, A.; Allain, J.; Chevallier, N.; Rouard, H. Morbidity of graft harvesting versus bone marrow aspiration in cell regenerative therapy. Int. Orthop. 2014, 38, 1855-1860. [CrossRef] [PubMed]

36. Krampera, M.; Franchini, M.; Pizzolo, G.; Aprili, G. Mesenchymal stem cells: From biology to clinical use. Blood Transfus. 2007, 5, 120-129. [PubMed]

37. Johnstone, B.; Hering, T.M.; Caplan, A.I.; Goldberg, V.M.; Yoo, J.U. In vitro chondrogenesis of bone marrow-derived mesenchymal progenitor cells. Exp. Cell Res. 1998, 238, 265-272. [CrossRef] [PubMed]

38. Caplan, A.I. Adult mesenchymal stem cells for tissue engineering versus regenerative medicine. J. Cell Physiol. 2007, 213, 341-347. [CrossRef] [PubMed]

(C) 2016 by the authors; licensee MDPI, Basel, Switzerland. This article is an open access article distributed under the terms and conditions of the Creative Commons by Attribution (CC-BY) license (http://creativecommons.org/licenses/by/4.0/). 